\title{
REVERSE HARDY-TYPE INEQUALITIES FOR SUPREMAL OPERATORS WITH MEASURES
}

\section{RZa Mustafayev And TuĞÇE ÜNVER}

Abstract. In this paper we characterize the validity of the inequalities

$$
\|g\|_{p,(a, b), \lambda} \leqslant c\|u(x)\| g\left\|_{\infty,(x, b), \mu}\right\|_{q,(a, b), v}
$$

and

$$
\|g\|_{p,(a, b), \lambda} \leqslant c\|u(x)\| g\left\|_{\infty,(a, x), \mu}\right\|_{q,(a, b), v}
$$

for all non-negative Borel measurable functions $g$ on the interval $(a, b) \subseteq \mathbb{R}$, where $0<p \leqslant$ $+\infty, 0<q \leqslant+\infty, \lambda, \mu$ and $v$ are non-negative Borel measures on $(a, b)$, and $u$ is a weight function on $(a, b)$.

Mathematics subject classification (2010): 26D10, 26D15, 46E30.

Keywords and phrases: Supremal operator, reverse Hardy-type inequality, Borel measures, weight functions, discretization.

\section{REFERENCES}

[1] W. D. Evans, A. Gogatishvili, B. Opic, The reverse Hardy inequality with measures, Math. Inequal. Appl. 11 (1), pp. 43-74, (2008).

[2] G. B. Folland, Real analysis, Pure and Applied Mathematics (New York), 2, Modern techniques and their applications; A Wiley-Interscience Publication, John Wiley \& Sons, Inc., New York, (1999).

[3] A. Gogatishvili, L. Pick, Discretization and anti-discretization of rearrangement-invariant norms, Publ. Mat., 47 (2), pp. 311-358, (2003).

[4] A. Kufner, L.-E. Persson, Weighted inequalities of Hardy type, World Scientific Publishing Co. Inc., River Edge, NJ, (2003).

[5] L. LEINDLER, Inequalities of Hardy-Littlewood type, Anal. Math., 2, pp. 117-123, (1976).

[6] L. Leindler, On the converses of inequalities of Hardy and Littlewood, Acta Sci. Math. (Szeged), 58 (1-4), pp. 191-196, (1993).

[7] B. Opic, A. Kufner, Hardy-type inequalities, Pitman Research Notes in Mathematics Series, 219, Longman Scientific \& Technical, Harlow, (1990).

[8] Walter Rudin, Principles of mathematical analysis, Second edition, McGraw-Hill Book Co., New York, (1964). 